\title{
Endoscopic repair of high-flow cranial base defects using a bilayer button.
}

\author{
Adam J. Luginbuhl \\ Thomas Jefferson University \\ Peter G. Campbell \\ Thomas Jefferson University \\ James Evans \\ Thomas Jefferson University \\ Marc Rosen \\ Thomas Jefferson University
}

Follow this and additional works at: https://jdc.jefferson.edu/otofp

Part of the Otolaryngology Commons, and the Surgery Commons

Let us know how access to this document benefits you

\section{Recommended Citation}

Luginbuhl, Adam J.; Campbell, Peter G.; Evans, James; and Rosen, Marc, "Endoscopic repair of high-flow cranial base defects using a bilayer button." (2010). Department of Otolaryngology Head and Neck Surgery Faculty Papers. Paper 8.

https://jdc.jefferson.edu/otofp/8

This Article is brought to you for free and open access by the Jefferson Digital Commons. The Jefferson Digital Commons is a service of Thomas Jefferson University's Center for Teaching and Learning (CTL). The Commons is a showcase for Jefferson books and journals, peer-reviewed scholarly publications, unique historical collections from the University archives, and teaching tools. The Jefferson Digital Commons allows researchers and interested readers anywhere in the world to learn about and keep up to date with Jefferson scholarship. This article has been accepted for inclusion in Department of Otolaryngology - Head and Neck Surgery Faculty Papers by an authorized administrator of the Jefferson Digital Commons. For more information, please contact: JeffersonDigitalCommons@jefferson.edu. 
As submitted to:

Laryngoscope

And later published as:

\title{
"Endoscopic repair of high-flow cranial base defects using a bilayer button"
}

\author{
Volume 120, Issue 5, May 2010, Pages 876-880
}

DOI: $10.1002 /$ lary.20861

Adam J. Luginbuhl MD, ${ }^{1}$ Peter G. Campbell MD ${ }^{2}$, James Evans MD², Marc Rosen MD ${ }^{1}$ Thomas Jefferson University, Philadelphia PA Departments of ${ }^{1}$ Otolaryngology Head and Neck Surgery and ${ }^{2}$ Neurosurgery

Running Title: Bilayer "Button" Closure

Funding source: None

Financial Disclosure/Conflict of Interest: None

Corresponding Author:

Adam Luginbuhl, MD

Thomas Jefferson University Hospital

Otolaryngology / Head and Neck Surgery

925 Chestnut St. 6th Floor

Philadelphia, PA 19107

aluginbuhl@gmail.com

215-240-0748 (c)

215-923-4532 (f) 
Oral Presentation at: $20^{\text {th }}$ North American Skull Base Society Meeting in New Orleans, LA - Oct $15^{\text {th }}-18^{\text {th }} 2009$.

Do not have CMYK capability

\begin{abstract}
Objective: Repair of the skull base still begins with a direct repair of the dural defect. We present a new button closure for primary repair of the dura for high flow defects.

Methods: We reviewed our 20 cases of primary button grafts and compared the results to the previous 20 high flow open cistern CSF cases. Subjects were excluded if they had no violation of the arachnoid space or potential for low-flow CSF leak. The "button" is constructed so that the inlay portion is at least $25 \%$ larger than the dural defect and the onlay portion is just large enough to cover the dural defect. The two grafts are sutured together using two \#4-0 neurolon sutures and placed with the inlay portion intradurally and the onlay portion extradurally.
\end{abstract}

Results: The button graft repair of open cisternal defects had a drop in CSF leak complications to $10 \%(2 / 20)$ and these 2 leaks were repaired with the button technique as the salvage surgery. This is a significant improvement over the $45 \%$ leak rate in the pre-button graft group $(\mathrm{p}<0.03)$. In our button graft group we used nasoseptal flaps on $16 / 20$ repairs and $1 / 2$ repairs that leaked in the button group did not have a nasoseptal flap. Lumbar drains were used in $\sim 38 \%$ in both groups $(\mathrm{p}=0.83$ ).

Conclusion: The button graft can be used in conjunction with the nasal septal flap or as a stand-alone repair with good results reducing the postoperative leak rate to $10 \%$ for high flow CSF repairs.

Key Words: CSF leak, Dural Defect Repair, Endoscopic Cranial Base Surgery 


\section{ENDOSCOPIC REPAIR OF HIGH FLOW CRANIAL BASE DEFECTS USING A BILAYER "BUTTON"}

\section{Introduction:}

Over the past 10 years, the surgical indications for complex resections through endoscopic endonasal cranial base approaches have been vastly expanded. The current boundaries of this type of resection range from the $2^{\text {nd }}$ vertebral body to the $3^{\text {rd }}$ ventricle. The underlying pathology often requires opening cisterns for complete resections. Thus, the resulting defects pose a colossal challenge to reconstruct and seal the sinonasal cavity from the subarachnoid space.

Historically, Dandy in 1926 described use of fascia lata in the repair of dural tears for pneumocephalus after traumatic frontal sinus injury ${ }^{1}$. In 1952 Hirsch reported the successful closure of a CSF leak via a non-pedicle septal flap thorough endonasal surgery ${ }^{2}$. Arguably the greatest advancement in cranial base defect repairs was the Hadad-Bassagasteguy flap (HBF) $)^{3,4}$, which employs a vascularized pedicle nasoseptal flap for mucosalized closure of the skull base. When faced with a high flow open cisternal defect all closures begin with direct repair of the dural defect. A variety of materials have been used for closure including fascia lata, fat and dural substitutes. Graft failure is usually the result of migration of the graft and subsequent CSF leakage. Many techniques have been described to stabilize the graft including the use of balloons, fat packing, gaskets and sutures ${ }^{3,5,6,7,8}$. These repairs often are supported by the vascularized nasoseptal pedicle flap. 
The senior authors (MR and JE) have attempted to design a new closure technique that would reduce cerebral spinal fluid (CSF) leak rates while keeping the design and application of the repair simple. This novel technique uses a "button graft" and other adjunctive techniques that have been effective at greatly reducing CSF leak rates at a tertiary care center. By concentrating on the biomechanical forces placed on the closure, this graft provides a simple closure option for large high-flow open-cistern defects after endoscopic cranial base surgery. A clear defining point exists between high-flow open cisternal defects and the closed cisterns with no or low flow leaks regarding their propensity to leak post operatively. In this study we were interested in only those with high-flow open cisterns.

\section{Methods:}

We reviewed our cases from 01/01/07 until 7/01/09 of endonasal skull base surgery with a resultant open-cistern and high-flow CSF leak. Midway through this study period the button graft was designed allowing for a comparison of button to the pre-button outcomes. The study was in accordance with the Institutional Review Board of the institution.

Preoperatively, the 2 main factors, which were considered indications for a button and/or septal flap, were a) tumor pathology and b) an approach that would lead to an open cistern/ventricle and resultant high-flow leaks. Minor factors included BMI, functional pituitary adenomas and the use of LD. The lateral thigh is sterilely prepped and draped in anticipation of a fascia lata harvest. The use of a spinal drain is decided 
by the senior surgeon based on the presumed location and size of the expected dural defect.

Prior to harvesting the fascia lata a pituitary rongeur is used to measure the extent of the dural defect (Figure 1a). Depending on patient size and size of graft needed an 8-12 cm incision is made over the lateral thigh on the upper $1 / 3$ between the greater trochanter and the knee in a caudal/rostral orientation, followed by blunt dissection to expose the fascia lata. A piece of fascia lata is harvested that is at least three times the length of the cranial defect and twice the width to allow for creation of the button graft. The button is assembled on the back table from two layers of fascia lata (Figure 1). The inlay, which will eventually sit on the inside of the dural defect, is cut $25-30 \%$ larger then the defect. The onlay graft is made to be only $5-10 \%$ larger than the opening. The onlay is centered on the inlay graft. Using two to four 4-0 Neurolon sutures (Ethicon, Bridgewater, New Jersey) they are yoked together by placing the sutures roughly $0.5 \mathrm{~cm}$ from the edge of the onlay graft leaving a flange of onlay graft that can overlap the dural defect (Figure I).

Adherence to this technique has allowed the authors to avoid filling the intradural space with a fat graft or other material. The graft is inserted into the sphenoid sinus and transported into the intradural space. The onlay leaflet is then pulled back through the defect leaving the inlay portion abutting the dura. Alternatively, the inlay sheet may be guided through the defect while a suction or grasper holds the onlay extradurally. Once the respective sheets of the graft are in the correct compartment a ring curette is used to smooth out both sheets. If the yoking sutures are placed in close 
proximity to the onlay edge these maneuvers become difficult. If sutures are positioned in the centermost portion of the graft the likelihood of graft migration and CSF leak around the graft is increased. Yoking the two sheets with the sutures in the appropriate position allows the inlay graft to be manipulated by simply moving the onlay graft in order to optimize the closure (Figure II). Subsequently, a mucoperichondrial septal flap (HBF) maybe reflected to provide a vascularized pedicle to the defect area. No additional fat or balloon packing is necessary to ensure graft stability. Finally, nasopore (Polyganics, Netherlands) and fibrin or biological glue is applied over the flap and graft. If no $\mathrm{HBF}$ is used then biological glue is applied on the onlay graft. In small defects, synthetic or collagen graft material has been used.

\section{Results:}

After employing the button graft to repair the dura on high-flow and opencisternal cases, the post-op CSF leak rate declined to $10 \%(2 / 20)$. This statistically significant improvement compares with $45 \%$ (9/20) leak rate in the pre-button graft group for open cistern defects $(\mathrm{p}<0.03)$ (Figure 3). The odds ratio for CSF leak after institution of button closure is $0.22(95 \%$ CI $0.04-0.92, p=0.037)$. Prior to the institution of the button technique, the dural repair consisted of fat packing to obliterate intracranial space followed by a synthetic dural inlay and onlay applied independently with liberal use of biologic glue. Pathologies included: 12 craniopharyngiomas, 5 meningiomas, 4 intracranial chordomas, 2 Rathke's pouch, 3 dural invasions of mucoceles, and individual cases of renal cell metastasis, encephalocele, chondrosarcoma and macroadenoma (table I). There was no difference in diagnosis between the two 
groups $(\mathrm{p}=0.45)$. Although the button group had 9 craniopharyngiomas opposed to the 4 in the pre-button group.

In the button graft group, concomitant nasoseptal flaps were employed in 16/20 repairs with only one CSF leak amongst this subpopulation. We employed the button technique without a nasoseptal flap in 4 cases and had one postop CSF leak after a craniopharyngioma resections. For the two patients that experiences post operative CSF leaks both were craniopharyngioma resections. One had a final repair with only a button graft and the second was repaired with both a new button graft and the reapplication of the nasoseptal graft.

In the button graft group lumbar drains were placed in $40 \%$ of patients $(8 / 20)$ at the initial surgery, which was not significantly different than the $35 \%$ use of LD in the pre-button group ( $\mathrm{p}=0.83)$. The average length of stay was 7 days for those without postoperative CSF leak versus 11 days for the 3 patients that needed further repair. The average volume of tumor was $1.7 \mathrm{~cm}$ (Figure 3$)^{3}$.

\section{Discussion:}

Defect repair after endoscopic cranial base surgery has been increasingly investigated as the indications for these procedures increase. The resultant CSF leakage after transnasal approaches to intracranial lesions not only results in increased length of stay and subsequent revision procedures, but also may delay prompt adjunctive therapies for treatment of the underlying disease such as radiation or chemotherapy. Factors that increase the likelihood of this complication include presence of intraoperative CSF leak, the lesion size, location and pathology as well as the size and location of cranial base 
defect. The authors propose a closure technique, which addresses the fundamental biomechanical instability, which commonly leads to postoperative CSF leaks. This method drastically reduces the complexity of current methods, while allowing for easy access to the cranial base should reoperation of the pathology be required.

By critically evaluating the non-button graft closure group, it was determined that failure occurred most often when graft migration postoperatively led to breakdown in healing at the edge of the dural repair. Most commonly, a superior edge was reported to be involved, which supports the hypothesis that gravitational effects caused the inlay graft to migrate inferiorly as if the graft was sliding down a cliff face and more anteriorly in cribiform plate defects the graft would simply drop away. In this group, occasionally it was observed that one of the free inlay or onlay sheets would have a tendency to pull away either due to dead space intracranially or CSF pressure pushing the graft internasally ${ }^{9}$. Adding fat or biologic glue to support these free inlay and onlay grafts did not substantially reduce the leak rate, but in fact added complexity and perhaps even contributed to shear forces and reduced graft-to-dural in growth and healing ${ }^{10}$. The addition of fat in a few cases was implicated in the mucosal over-growth found on the epidural side.

Several centers have described novel techniques for closure of open cisterns after endoscopic surgery. Lang et al. described 10 patients after repair with a "gasket method" whereby harvested vomer bone was wedged into place over a facial graft ${ }^{8}$. This technique also addresses the gravitational and shear forces that act on a traditional multi- layer closure. In this pilot data they had a $0 \%$ leak rate. The irregular contours of 
the skull base could conceivably make the 'wedge' fit difficult to obtain in certain locations for example where the resultant defect crosses from tuberculum sella and the planum sphenoidale. In this series, Lang reported the use of intracranial fat packing, which was not used in any of our button grafted patients. Multiple other repair techniques have been proposed in the current literature, ranging from synthetic material $^{6,11}$ to reconstruction of bony defects ${ }^{12,13,14}$. The use of vascularized tissue has allowed considerable improvement in closure of cranial base defects ${ }^{3,5,15,16,17}$. HadadBassagasteguy flap (HBF) is a vascular pedicle of the nasal septum mucoperiosteum and mucoperichondrium based on the nasoseptal artery, which has drastically reduced the CSF leak rate to roughly $5 \%$ and has been coupled with numerous techniques of primary dural repair ${ }^{3,4}$. As a total repair this method has proven extremely effective, but it has often required the use of a balloon catheter stent to address the mechanical forces that predispose to repair failure. Whereas, the proposed button graft provides the cranial base surgeon with a novel technique that when combined with the HBF provides excellent closure and has avoided the need for the balloon catheter stent. Post-operative patient satisfaction is increased and the likelihood of sinus drainage interference and septal injury has decreased.

Kassam et al. (2008) quoted 5\% for repairs in both high and low flow defects with $1 / 3$ of the HBF for pituitary adenomas ${ }^{17}$. At our institution we reserve the button graft and HBF only for high-flow defects and our low-flow defects are repaired using synthetic onlay material. More recently Zanation et al (2009) has published a series of 70 consecutive $\mathrm{HBF}$ repairs with a resultant $6 \%$ leak rate overall and a $10 \%$ leak rate in 
the 42 patients with large dural openings. This series also included 21 patients with

pituitary adenoma resections ${ }^{18}$. This is consistent with our resultant $10 \%(2 / 20)$ leak rate for high-flow open cisternal defects.

\section{Conclusion:}

"Button" graft provides the cranial base surgeon with an additional novel repair technique that has demonstrated effectiveness at sealing the dural defect and reducing CSF leaks. Use of the Button graft has allowed us to avoid fat grafts, implants, problems with graft migration, balloon catheters or other packing agents. This procedure addresses the biomechanical forces that are commonly placed on the closure postoperatively, thereby reducing the incidence of CSF leak. The graft has been used successfully both with and without the use of the nasal septal flap. 


\section{References:}

1) Dandy W. Pneumocephalus (Intracranial pneumatocele or aerocele). Archives of Surgery 1926; 12:959-982.

2) Hirsch O. Successful closure of cerebrospinal fluid rhinorrhea by endonasal surgery. Archives of Otolaryngology 1952; 56:1-12.

3) Fortes F, Carrau R, Synderman C. Transpterygoid transposition of a temporoparietal fascia flap: A new method for skull base reconstruction after endoscopic expanded endonasal approaches. Laryngoscope 2007; XXX:970976.

4) Hadad. G, Bassagasteguy M, Carrau R. A Novel reconstructive technique after endoscopic expanded endonasal approaches: Vascular pedicle nasoseptal flap. Laryngoscope 2006; 116:1882-1886.

5) Kassam A, Carrau R, Snyderman C. Evolution of reconstructive techniques following endoscopic expanded endonasal approaches. Neurosurg Focus 2005; 19:E8.

6) Seiler R, Mariani L. Sellar reconstruction with resorbable vicryl patches, gelatin foam, and fibrin glue in transsphenoidal surgery: A 10 year experience with 376 patients. Journal of Neurosurgery 2000; 93:762-765.

7) Cukurova I, Cetinkaya E, Aslan I. Endonasal endoscopic repair of ethmoid roof cerebral fluid fistula by suturing the dura. Acta Neurochir 2008; 10: 7-10. 
8) Leng L, Seth B, Vijay, Schwartz T. "Gasket Seal” Watertight closure in minimal-access endoscopic cranial base surgery. Neurosurgery 2008; 62: ONSE 342-343.

9) Charalampaki P, Heimann A, Kopacz L. New method of bone reconstruction designed for skull base surgery. Journal of Clinical Neuroscience 2006; 15:679685.

10) Hagazy H, Carrau R, Snyderman C. Transnasal endoscopic repair of cerebrospinal fluid rhinorrhea: A meta-analysis. Laryngoscope 2000; 110:1161172.

11) Cappabianca P, Cavallo L, Mariniello G. Easy sellar reconstruction in endoscopic endonasal transsphenoidal surgery with polyester-silicone dural substitute and fibrin glue: Technical note. Neurosurgery 2001; 49:473-476

12) Cavallo L, Messina A, Esposito F. Skull base reconstruction in the extended endoscopic transsphenoidal approach for suprasellar lesions. Journal of Neurosurgery 2007; 107:713-720.

13) Arita K, Kurisu K, Tominaga A. Size-adjustable titanium plate for reconstruction of the sella turcica. Technical note. Journal of Neurosurgery 1999; 91:1055-1057.

14) Kabuto M, Kubota T, Kobayashi H. Long-term evaluation of reconstruction of the sellar floor with silicone plate in transsphenoidal surgery. Journal of Neurosurgery 1998; 88:949-953. 
15) Snyderman C, Janecka I, Sekhar L. Anterior cranial base reconstruction : role of galeal and pericranial flaps. Laryngoscope 1990; 100:607-614.

16) Fortes F, Carrau R, Snyderman C. The posterior pedicle inferior turbinate flap: A new vascularized flap for skull base reconstruction. Laryngoscope 2007; 117 : 1329-1332.

17) Kassam AB, Thomas A, Carrau RL. Snyderman CH, Vescan A, Prevedello D, Mintz A, Gardner P. Endoscopic reconstruction of the cranial base using a pedicled nasoseptal flap. Neurosurgery 2008; 63/(1 suppl 1): ONS44-52.

18) Zanation A, Carrau R, Snyderman C, Germanwala A, Gardner P, Prevedello D, Kassam A. Nasoseptal flap reconstruction of high flow intraoperative cerebral spinal fluid leaks during endoscopic skull base surgery. American Journal of Rhinology and Allergy 2009; 23:518-21. 


\section{Figure Legions:}

Table I: Pathology associated with high flow CSF defect

Figure 1: A: Cistern defect 1X2 cm), s/p craniopharyngioma resection. The optic chiasm is present with CSF visible. B: Fascia lata button graft with sutures in place. C/D: Placement of yoking suture

Figure II: A/B) Schematic of inlay/onlay layers in relationship to dural defect. C: Post repair of defect with onlay portion visible only.

Figure 3: Outcomes of button verses pre-button repair. CSF leak $p=0.03$. LOS and lumbar drain: $\mathrm{p}=$ Non-significant 